\title{
Catalytic Conversion of Biomass
}

\author{
Rafael Luque, Sudipta De and Alina M. Balu \\ Departamento de Quimica Organica, Universidad de Cordoba, Campus de Rabanales, \\ Edificio Marie Curie (C-3), Ctra Nnal IV-A, Km 396, Cordoba 14014, Spain; q62alsor@uco.es (R.L.); \\ sudiptade22@gmail.com (S.D.); qo2balua@uco.es (A.M.B.) \\ Academic Editor: Keith Hohn \\ Received: 6 September 2016; Accepted: 14 September 2016; Published: 22 September 2016
}

Petroleum, natural gas and coal supply most of the energy consumed worldwide and their massive utilization has allowed our society to reach high levels of development in the past century. The shift towards a bio-based economy has been recently promoted with ambitious targets to replace an important fraction of fossil fuels by renewable sources within 20 years. Biomass emerged as a highly suitable alternative for this bio-based revolution as an ideal substitute for petroleum in the production of fuels, chemicals and carbon-based materials. Consequently, a number of ongoing efforts have been devoted to biomass conversion/valorization towards valuable products using a number of (bio)catalytic strategies.

Based on these premises, the present Special Issue of Catalysts was aimed to provide a number of broad and multifaceted contributions in the field of catalytic biomass conversion towards the production of high added value products from sugars (hemicellulose and cellulose fraction) and lignin as well as related biomass conversion strategies.

In this regard, Song et al. contributed to develop an efficient dehydration of fructose to HMF using heteropolyacid salts [1]. Along similar lines, two additional contributions for the Special Issue from Li et al. [2] and Fachri et al. [3] disclosed the catalytic aqueous conversion of glucose and inulin into HMF using Lewis acid and metal salts catalysts, respectively, providing also interesting modelling insights into the proposed chemistries.

The produced furanic derivatives in these contributions as well as related compounds (e.g., sorbitol) have also promising prospects to be further upgraded to fuel components for blends. Pizzi et al. provided a nice approach towards high throughput screening of a range of heterogeneous catalysts for the conversion of furfural to bio-based fuel components [4] in a similar way to the approach proposed by Iglesias et al. for the conversion of furfural to furfuryl alcohol via Meerwein-Ponndorf-Verley reduction using Zr-SBA-15 [5], while valuable jet-fuel range hydrocarbons could also be produced from biomass-derived sorbitol using Ni-HZSM-5/SBA-15 catalysts [6]. Such biomass-engineered products have a significant potential to replace current petroleum-derived analogues with improved biocompatibility and a reduced environmental footprint.

Levulinic acid and levulinates are related interesting platform molecules that can be derived from biomass and subsequently upgraded towards chemicals and biofuel precursors. Along these lines, Wang et al. proposed the utilization of cheap and environmentally friendly $\mathrm{Nb} / \mathrm{Al}$ oxide catalysts for the conversion of kiwifruit waste to levulinic acid [7]. Additionally, the direct conversion of carbohydrates into ethyl levulinate using potassium phosphotungstate as efficient catalyst was reported by Zhao et al. [8]. Further conversion of levulinic acid to gamma-valerolactone (GVL) could also take place efficiently on nickel/alumina catalysts [9].

Hydrogenation and hydrodeoxygenation of lignin and lignocellulosic pyrolysis has also been another hot topic in recent times due to the possibility to produce aromatics and cyclic derivatives from biomass. Yi et al. proposed a highly efficient hydrogenation of lignin derived monophenols towards cyclohexanols using Pd/alumina catalysts [10]. Co-pyrolysis behavior of cotton straw 
mixtures and their catalytic hydrodeoxygenation were also investigated by Hua et al. [11] using $\mathrm{Ni}-\mathrm{Mo} /$ alumina catalysts.

Additional contributions to the Special Issue included the selective production of aromatics from 2-octanol on Zn-exchanged MFI zeolites [12], the electrocatalytic oxidation of cellulose to gluconate on carbon aerogel supported gold nanoparticles anodes [13] and the steam reforming of bioethanol to hydrogen catalyzed by Co/ceria catalysts [14].

The Guest Editors sincerely hope that the results presented as part of this Special Issue of most varied topics can serve as a starting point for further innovations in the catalytic conversion of biomass and look forward to enjoying further improvements in the aforementioned topics and fields in the future.

\section{References}

1. Kalevaru, V.N.; Dhachapally, N.; Martin, A. Catalytic Performance of Lanthanum Vanadate Catalysts in Ammoxidation of 2-Methylpyrazine. Catalysts 2016, 6, 10. [CrossRef]

2. Li, J.; Ma, Y.; Wang, L.; Song, Z.; Li, H.; Wang, T.; Li, H.; Eli, W. Catalytic Conversion of Glucose into 5-Hydroxymethylfurfural by $\mathrm{Hf}(\mathrm{OTf})_{4}$ Lewis Acid in Water. Catalysts 2016, 6, 1. [CrossRef]

3. Fachri, B.A.; Rasrendra, C.B.; Heeres, H.J. Experimental and Modeling Studies on the Conversion of Inulin to 5-Hydroxymethylfurfural Using Metal Salts in Water. Catalysts 2015, 5, 2287-2308. [CrossRef]

4. Pizzi, R.; van Putten, R.-J.; Brust, H.; Perathoner, S.; Centi, G.; van der Waal, J.C. High-Throughput Screening of Heterogeneous Catalysts for the Conversion of Furfural to Bio-Based Fuel Components. Catalysts 2015, 5, 2244-2257. [CrossRef]

5. Iglesias, J.; Melero, J.A.; Morales, G.; Moreno, J.; Segura, Y.; Paniagua, M.; Cambra, A.; Hernández, B. Zr-SBA-15 Lewis Acid Catalyst: Activity in Meerwein Ponndorf Verley Reduction. Catalysts 2015, 5, 1911-1927. [CrossRef]

6. Weng, Y.; Qiu, S.; Ma, L.; Liu, Q.; Ding, M.; Zhang, Q.; Zhang, Q.; Wang, T. Jet-Fuel Range Hydrocarbons from Biomass-Derived Sorbitol over Ni-HZSM-5/SBA-15 Catalyst. Catalysts 2015, 5, 2147-2160. [CrossRef]

7. Wang, R.; Xie, X.; Liu, Y.; Liu, Z.; Xie, G.; Ji, N.; Ma, L.; Tang, M. Facile and Low-Cost Preparation of Nb/Al Oxide Catalyst with High Performance for the Conversion of Kiwifruit Waste Residue to Levulinic Acid. Catalysts 2015, 5, 1636-1648. [CrossRef]

8. Zhao, S.; Xu, G.; Chang, C.; Fang, S.; Liu, Z.; Du, F. Direct Conversion of Carbohydrates into Ethyl Levulinate with Potassium Phosphotungstate as an Efficient Catalyst. Catalysts 2015, 5, 1897-1910. [CrossRef]

9. Fu, J.; Sheng, D.; Lu, X. Hydrogenation of Levulinic Acid over Nickel Catalysts Supported on Aluminum Oxide to Prepare $\gamma$-Valerolactone. Catalysts 2016, 6, 6. [CrossRef]

10. Yi, J.; Luo, Y.; He, T.; Jiang, Z.; Li, J.; Hu, C. High Efficient Hydrogenation of Lignin-Derived Monophenols to Cyclohexanols over Pd $/ \gamma-\mathrm{Al}_{2} \mathrm{O}_{3}$ under Mild Conditions. Catalysts 2016, 6, 12. [CrossRef]

11. Hua, D.; Wu, Y.; Chen, Y.; Li, J.; Yang, M.; Lu, X. Co-Pyrolysis Behaviors of the Cotton Straw/PP Mixtures and Catalysis Hydrodeoxygenation of Co-Pyrolysis Products over Ni-Mo/ $\mathrm{Al}_{2} \mathrm{O}_{3}$ Catalyst. Catalysts 2015, 5, 2085-2097. [CrossRef]

12. Iwamoto, M.; Takezawa, R.; Morimoto, M. Selective Production of Aromatics from 2-Octanol on Zinc Ion-Exchanged MFI Zeolite Catalysts. Catalysts 2015, 5, 2122-2133. [CrossRef]

13. Xiao, H.; Wu, M.; Zhao, G. Electrocatalytic Oxidation of Cellulose to Gluconate on Carbon Aerogel Supported Gold Nanoparticles Anode in Alkaline Medium. Catalysts 2016, 6, 5. [CrossRef]

14. Liu, Y.; Murata, K.; Inaba, M. Steam Reforming of Bio-Ethanol to Produce Hydrogen over $\mathrm{Co} / \mathrm{CeO}_{2}$ Catalysts Derived from $\mathrm{Ce}_{1-x} \mathrm{Co}_{x} \mathrm{O}_{2-y}$ Precursors. Catalysts 2016, 6, 26. [CrossRef]

(C) 2016 by the authors; licensee MDPI, Basel, Switzerland. This article is an open access article distributed under the terms and conditions of the Creative Commons Attribution (CC-BY) license (http://creativecommons.org/licenses/by/4.0/). 